\title{
Nephroprotective effect of silymarin against diclofenac- induced renal damage and oxidative stress in male rats
}

\author{
Ali Nouri $^{*}$, Esfandiar Heidarian \\ Clinical Biochemistry Research Center, Basic Health Sciences Institute, Shahrekord University of Medical Sciences, Shahrekord, Iran
}

A R T I C L E I N F O

Article Type:

Original Article

\section{Article History:}

Received: 24 November 2018

Accepted: 10 February 2019

\section{Keywords:}

Oxidative stress

Silymarin

TNF-a

Diclofenac

Renal damage

\begin{abstract}
A B S T R A C T
Introduction: Diclofenac (DIC), a phenylacetic acid compound which belongs to nonsteroidal anti-inflammatory drugs (NSAIDs), is generally used for the treatment of various diseases such as rheumatoid arthritis, ankylosing spondylitis, acute muscle pain conditions and osteoarthritis. Overdose of DIC can lead to renal injuries in both experimental animal and human. Our research was done to assess the protective role of silymarin on renal damage induced by DIC in rats.

Methods: Thirty-two Wistar rats were assigned to four groups ( $\mathrm{n}=8$ /group). Group 1 was control group; animals in group 2 were administrated DIC; Groups 3 and 4 administrated DIC plus silymarin with doses of $100 \mathrm{mg} / \mathrm{kg}$ and $200 \mathrm{mg} / \mathrm{kg}$, orally (p.o), respectively. Various biochemical, molecular, and histological parameters were evaluated in serum and tissue homogenate.

Results: In the second group, the levels of kidney catalase (CAT), vitamin C and superoxide dismutase $(\mathrm{SOD})$ remarkably reduced $(P<0.05)$ relative to the control group. Also, urea, creatinine (Cr), malondialdehyde (MDA), serum tumor necrosis factor- $\alpha$ (TNF- $\alpha$ ) and gene expression of $T N F-\alpha$ in this group were noticeably elevated $(P<0.05)$ relative to the control group. Treatment with silymarin caused a remarkable elevation $(P<0.05)$ in vitamin $C$, SOD, CAT and a remarkable reduction $(P<0.05)$ in the content of MDA, urea, Cr, TNF- $\alpha$ gene expression and serum TNF- $\alpha$ in comparison with second group. Histological injuries were also ameliorated by silymarin administration.

Conclusion: The results confirm that silymarin has an ameliorative role against renal damage and oxidative stress induced by DIC in male rats.
\end{abstract}

Implication for health policy/practice/research/medical education:

The study demonstrated silymarin nephroprotective activity recommending its potential benefits for the treatment of kidney injuries.

Please cite this paper as: Nouri A, Heidarian E. Nephroprotective effect of silymarin against diclofenac-induced renal damage and oxidative stress in male rats. J Herbmed Pharmacol. 2019;8(2):146-152. doi: 10.15171/jhp.2019.23.

\section{Introduction}

Usually, a mixture of biochemical and physiological phenomena play a role in kidney susceptibility and renal toxicity. The kidney is highly sensitive to chemical poisoning, compared to other organs, partly due to its unequally high blood flow, and because of its complexity both functionally and anatomically. This organ also plays an important role in regulation of blood pressure. Urine is the main pathway that most of the poisons are repelled. Eventually, nephrons condense poisons in the filtration and transport those across the tubular cells (1). Nonsteroidal anti-inflammatory drugs (NSAIDs) are variety of chemical drugs that have similar attributes and are applied for control of inflammation and pain. The normal doses of NSAIDs only cause gastrointestinal incompatibility. However, consumption of high doses of these drugs (such as: ibuprofen, diclofenac [DIC], and naproxen) can lead to toxicity $(2,3)$. DIC is the most common NSAID used to decrease inflammation and arthritis-associated pain $(4,5)$. It is absorbed quickly and completely after consumption and attaches to albumin in plasma (6). Gastrointestinal side effects are the most common abnormal complications of DIC, although nephrotoxicity and liver toxicity are also related to DIC intoxication $(7,8)$. All of these characteristics 
make the kidneys highly susceptible to various types of abnormalities.

Silymarin, a flavonoid compound, is derivated from Silybum marianum seeds. It is a combination of silydianine, silychristine, isosilybinin and silibinin. Silymarin creates a protective role in liver because of its radical scavenger effects (9). Silymarin has antioxidant properties and stabilizes cell membranes and also regulates the intracellular GSH (reduced glutathione) and chelates metal (copper and iron) ions $(10,11)$. There are many pharmacological agents which are associated with renal injury. Preventing renal toxicity with use of inexpensive and useful drugs reduces hospitalization expenditure, also extenuate the rates of morbidity and mortality. To the best of our information, there are not investigations concerning the renal protective role of silymarin on intoxication of DIC. Accordingly, this research was aimed to assess the noxious effect of acute DIC intoxication on the kidney through evaluation of serum biochemical markers, oxidative stress, gene expression of tumor necrosis factor- $\alpha$ (TNF- $\alpha$ ) and histological alterations.

\section{Materials and Methods}

Chemicals

Chemicals such as 2-thiobarbituric acid, sodium acetate, and $\mathrm{H} 2 \mathrm{O} 2$ were prepared from Merck (Darmstadt, Germany). TPTZ (2,4,6-tripyridyl-s-triazine), silymarin and nitro blue tetrazolium were purchased from SigmaAldrich (St. Louis, MO). SYBR Green Real-Time PCR Master Mix was provided from Qiagen Co. (Dusseldorf, Germany). Urea and creatinine (Cr) were measured using Pars Azmun Company (Tehran, Iran). All other chemicals which employed in this study were of analytical grade. Animals

Thirty-two male Wistar rats weighting around $200 \pm 20$ g (6-8 weeks old) were obtained from Jondi-Shapour University (Ahwaz, Iran). The animals were kept in standard condition (temperature $23 \pm 2^{\circ} \mathrm{C}$, free access to water and food, and a 12:12 h light- dark cycle) and housed four per cage. The rats were accustomed for 7 days before the initiation of the experiment.

\section{Experimental design}

The rats were divided randomly into four groups each comprising of eight animals. Group 1, control group, was treated with normal saline $(1 \mathrm{ml} / \mathrm{kg}$ body weight (bw), i.p.) and $0.5 \mathrm{~mL}$ distilled water as the solvent of silymarin by gavage an hour later for 5 days to provide equal shock in the control group as opposed to other groups. Group 2 received DIC only (50 $\mathrm{mg} / \mathrm{kg}$ bw, i.p.) and $0.5 \mathrm{~mL}$ distilled water as solvent of silymarin by gavage an hour later for 5 days to provide equal shock in the control group as opposed to other groups $(12,13)$. Group 3 received DIC (50 mg/kg bw, i.p.) plus silymarin (100 mg/kg bw, p.o) an hour later for 5 days (12-15). Group 4 received DIC (50 $\mathrm{mg} / \mathrm{kg}$ bw, i.p.) plus silymarin (200 mg/kg bw, p.o) an hour later for 5 days $(12,16)$. At the end of the study, the fasted rats were sacrificed under mild chloroform anesthesia. Whole blood samples were collected by cardiac puncture method. The serum and plasma were prepared at 2000 RPM for 10 minutes. Also, kidney tissue was harvested for determining kidney catalase (CAT) and superoxide dismutase (SOD) activities, expression of TNF- $\alpha$ gene and histological studies.

Biochemical analysis

Serum urea and Cr levels were measured by an enzymatic method (Pars Azmun kit, Pars Azmun Company, Tehran, Iran) using autoanalyzer (BT 3000, Biotecnica, Cergy Pontoise Cedex, France). Serum TNF- $a$ was assessed using the ELISA assay kit (BT-Laboratory, China) according to the procedure provided by the manufacturer.

Determination of plasma antioxidant capacity

Ferric reducing/antioxidant power (FRAP) was determined by Heidarian and Soofiniya procedure using tripyridyl-triazine (17).

Determination of kidney vitamin C

Renal tissue level of vitamin $\mathrm{C}$ was determined by 2,4-dinitrophenylhydrazine as describe by Omaye et al (18).

\section{Estimation of lipid peroxidation (MDA)}

Thiobarbituric acid as reagent was used to determine serum and renal malondialdehyde (MDA) which formed a pink complex with MDA as reported in details previously (17).

Determination of tissue CAT and SOD activities The kidney CAT activity of experimental groups was measured as reported in details previously (19). The activity of renal SOD was evaluated using the inhibition of the NBT photo chemical reaction at $560 \mathrm{~nm}$ (20). All total protein samples were assessed using the method of Bradford (21).

Assessment of kidney TNF- $\alpha$ gene expression Gene expression of TNF- $\alpha$ on the kidney experimental groups was assessed as described previously (22). $\beta$-actin was used as a housekeeping gene for normalizing the data.

\section{Histopathological study}

A segment of each kidney was fixed in $20 \%$ formalin solution. All samples were embedded in paraffin and $5 \mu \mathrm{m}$ thickness sections were prepared. Then, the slices stained with hematoxylin-eosin ( $\mathrm{H} \& \mathrm{E}$ ) for histopathological observation (23). 
Statistical analysis

One-way analysis of variance (ANOVA) was used for data analysis using SPSS software (Statistical Package for the Social Sciences, version 20.0, SPSS Inc, Chicago, IL). All data were expressed as mean \pm SD. Also, DDCT method was used for analysis of TNF- $\alpha$ gene expression. Mean values of the groups were compared using the Tukey post hoc test. $P<0.05$ was statistically considered significant.

\section{Results}

Effects of silymarin on serum urea and creatinine

The effects of DIC and silymarin on serum $\mathrm{Cr}$ and urea are shown in Table 1. In group 2, administration of DIC led to a noticeable elevation $(P<0.05)$ in serum $\mathrm{Cr}$ and urea relative to the normal group (Table 1). However, in groups 3 and 4, administration of silymarin resulted in a remarkable decline $(P<0.05)$ in serum $\mathrm{Cr}$ and urea relative to the second group.

Effects of silymarin on MDA levels and plasma FRAP The effects of Silymarin on plasma FRAP, tissue MDA and serum MDA levels are shown in Table 2. In group 2 (DIC-only treated group), administration of DIC resulted in a noticeable decrease $(P<0.05)$ in plasma FRAP and an increase in tissue and serum MDA levels relative to the normal group (group 1). Treatment with silymarin in groups 3 and 4 caused a remarkable increase $(P<0.05)$ in plasma antioxidant capacity and a significant decrease $(P<0.05)$ in tissue and serum MDA levels relative to second group. Also, a remarkable alteration $(P<0.05)$ was seen in plasma FRAP, serum MDA and renal MDA between the third (silymarin-treated group with $100 \mathrm{mg}$ / $\mathrm{kg}$ ) and fourth (silymarin-treated group with $200 \mathrm{mg} / \mathrm{kg}$ ) groups.
Effects of silymarin on CAT activity, SOD activity and vitamin $\mathrm{C}$ level

Table 3 shows that injection of DIC led to a noticeable reduction $(P<0.05)$ in renal CAT activity in second group (DIC-only group) relative to the normal group (group 1). A considerable increase $(P<0.05)$ in kidney CAT activity was observed in silymarin-treated groups relative to the second group (DIC-only group). Table 3 also shows a remarkable decrease $(P<0.05)$ in renal SOD activity in the second group (DIC-only treated group) when compared with the control group. However, administration of silymarin in third and fourth groups caused a significant elevation $(P<0.05)$ in renal SOD activity relative to the second group. Also injection of DIC in DIC-only treated group (group 2) led to a noticeable reduction $(P<0.05)$ in kidney vitamin $C$ relative to the normal group (Table3). However, in groups treated with doses of 100 and 200 $\mathrm{mg} / \mathrm{kg}$ silymarin (groups 3 and 4), kidney vitamin C remarkably elevated $(P<0.05)$ relative to the DIC-only treated group (group 2).

The effects of silymarin on serum and gene expression of $T N F-\alpha$

The effects of silymarin on serum content of TNF- $\alpha$ and TNF- $\alpha$ gene expression are shown in Figure 1. DIC injection in group 2 led to a remarkable elevation $(P<0.05)$ in serum content of TNF- $\alpha$ and TNF- $\alpha$ gene expression relative to the normal group (group 1). On the other hand, treatment with silymarin caused a remarkable decrease $(P<0.05)$ in serum content of TNF- $\alpha$ and TNF- $\alpha$ gene expression relative to the second group (DIC-only treated group). A noticeable change $(P<0.05)$ was seen in serum content of TNF- $\alpha$ and TNF- $\alpha$ gene expression in the third group (treated with doses of $100 \mathrm{mg} / \mathrm{kg}$ silymarin) relative

Table 1. Effect of silymarin on serum urea and creatinine

\begin{tabular}{llll}
\hline Parameters $(\mathrm{mg} / \mathrm{dL})$ & Group 1 & Group 2 & Group 3 \\
\hline Urea & $29.85 \pm 2.36$ & $54.25 \pm 3.53^{\mathrm{a}}$ & $36.86 \pm 2.98^{\mathrm{ab}}$ \\
Creatinine & $0.81 \pm 0.09$ & $1.88 \pm 0.18^{\mathrm{a}}$ & $0.91 \pm 0.1^{\mathrm{b}}$ \\
\hline
\end{tabular}

Data are expressed as mean \pm SEM $(n=8)$ and analyzed by one-way ANOVA followed by Tukey post hoc test. Group 1: normal group; group 2: diclofenac only; groups 3 and 4 were treated by diclofenac plus silymarin with doses of $100 \mathrm{mg} / \mathrm{kg}$ and $200 \mathrm{mg} / \mathrm{kg}$, respectively.

${ }^{a} P<0.05$ versus control group (group 1 ).

${ }^{\mathrm{b}} P<0.05$ versus diclofenac administered group (group 2).

${ }^{c} P<0.05$ versus group treated with $100 \mathrm{mg} / \mathrm{kg}$ silymarin (group 3).

Table 2. Effect of silymarin on ferric reducing/antioxidant power (FRAP) and malondialdehyde (MDA) levels in the experimental groups

\begin{tabular}{lllll}
\hline Parameters & Group 1 & Group 2 & Group 3 & Group 4 \\
\hline Serum FRAP $(\mu \mathrm{M})$ & $526.27 \pm 31.22$ & $374.26 \pm 27.41^{\mathrm{a}}$ & $498 \pm 37.64^{\mathrm{b}}$ & $612.25 \pm 48.66^{\mathrm{abc}}$ \\
Serum MDA $(\mu \mathrm{M})$ & $8.43 \pm 2.52$ & $19.68 \pm 3.18^{\mathrm{a}}$ & $13.65 \pm 2.15^{\mathrm{ab}}$ & $8.17 \pm 1.87^{\mathrm{bc}}$ \\
Renal MDA $(\mu \mathrm{mol} / \mathrm{mg}$ protein) & $1.91 \pm 0.71$ & $5.51 \pm 1.15^{\mathrm{a}}$ & $3.56 \pm 0.76^{\mathrm{ab}}$ & $1.87 \pm 0.58^{\mathrm{bc}}$ \\
\hline
\end{tabular}

Data are expressed as mean \pm SEM $(n=8)$ and analyzed by one-way ANOVA followed by Tukey post hoc test. Group 1: normal group; group 2: diclofenac only; groups 3 and 4 were treated by diclofenac plus silymarin with doses of $100 \mathrm{mg} / \mathrm{kg}$ and $200 \mathrm{mg} / \mathrm{kg}$, respectively.

a $P<0.05$ versus control group (group 1 ).

${ }^{\mathrm{b}} P<0.05$ versus diclofenac administered group (group 2).

${ }^{c} P<0.05$ versus group treated with $100 \mathrm{mg} / \mathrm{kg}$ silymarin (group 3). 
Table 3. Effect of silymarin on catalase (CAT) activity, superoxide dismutase (SOD) activity and vitamin C level in the experimental groups

\begin{tabular}{|c|c|c|c|c|}
\hline Parameters & Group 1 & Group 2 & Group 3 & Group 4 \\
\hline CAT (U/mg protein) & $165.32 \pm 14.32$ & $55.27 \pm 6.12^{\mathrm{a}}$ & $112.87 \pm 9.76^{\mathrm{ab}}$ & $167 \pm 15.13^{\mathrm{bc}}$ \\
\hline SOD (U/mg protein) & $46.32 \pm 4.12$ & $27.61 \pm 2.89^{\mathrm{a}}$ & $37.21 \pm 3.13^{\mathrm{ab}}$ & $47.43 \pm 3.98^{b c}$ \\
\hline Vitamin C (mg/g of wet kidney) & $15.45 \pm 2.12$ & $8.87 \pm 1.12^{\mathrm{a}}$ & $12.78 \pm 1.76^{b}$ & $15.88 \pm 2.68^{b}$ \\
\hline
\end{tabular}

Data are expressed as mean \pm SEM $(n=8)$ and analyzed by one-way ANOVA followed by Tukey post hoc test. Group 1: normal group; group 2: diclofenac only; groups 3 and 4 were treated by diclofenac plus silymarin with doses of $100 \mathrm{mg} / \mathrm{kg}$ and $200 \mathrm{mg} / \mathrm{kg}$, respectively.

a $P<0.05$ versus control group (group 1 ).

${ }^{\mathrm{b}} P<0.05$ versus diclofenac administered group (group 2).

${ }^{\mathrm{c}} P<0.05$ versus group treated with $100 \mathrm{mg} / \mathrm{kg}$ silymarin (group 3).


Figure 1. Effect of silymarin on serum tumor necrosis factor- $\alpha$ (TNF- $\alpha)$ and expression of TNF- $\alpha$. Each value represents the mean \pm SEM of eight rats. Group 1: normal group; group 2: diclofenac only; groups 3 and 4 were treated by diclofenac plus silymarin with doses of $100 \mathrm{mg} / \mathrm{kg}$ and $200 \mathrm{mg} / \mathrm{kg}$, respectively.

a $P<0.05$ versus control group (group 1).

${ }^{\mathrm{b}} P<0.05$ versus diclofenac administered group (group 2).

${ }^{c} P<0.05$ versus group treated with $100 \mathrm{mg} / \mathrm{kg}$ silymarin (group 3 ).

to the fourth group (treated with doses of $200 \mathrm{mg} / \mathrm{kg}$ silymarin).

Histopathological findings

The histological results of kidney from the experimental groups are demonstrated in Figure 2. The microscopic examination depicted normal structures of kidney tissue from a normal rat in control group (Figure 2A). Administration of DIC-only in group 2 showed mononuclear cells filtration and histological changes compared to the control group that reflected renal damage (Figure 2B). The decrease of inflammatory cell infiltration was observed in silymarin-treated groups (Figure 2C-D) relative to the second group (DIC-only treated group). The decrease of inflammatory cells in the fourth group (silymarin-treated group with dose of $200 \mathrm{mg} / \mathrm{kg}$ ) was more than the third group (silymarin-treated group with dose of $100 \mathrm{mg} / \mathrm{kg}$ ).

\section{Discussion}

About $60 \%$ of hospital-acquired acute kidney injury is due to drug-induced nephrotoxicity, which is a main reason of morbidity and mortality. Multiple factors, such as dose regulation based on renal function, hydration and avoidance of nephrotoxic agents, have been suggested to prevent or improve drug-induced nephrotoxicity $(24,25)$. Nevertheless, drug induced toxicity remains a major problem for health care specialists. Therefore, finding impressive approaches to reduce renal injuries are of notable importance. Silymarin is widely used as a hepatoprotective medication. Anti-inflammatory and antioxidant actions, deterrence of lipid peroxidation, protein synthesis induction, neutrophil migration and leukotriene and prostaglandin synthesis are pharmacologically depicted effects of silymarin bioflavonoids (26-28). Silymarin may show positive effects in the management of patients with renal injuries.

Our findings that DIC causes acute renal injury manifested as significant urea and $\mathrm{Cr}$ elevations. In our research, kidney histological findings depicted that injection of DIC caused renal damage (Figure 2) accompanied with elevates in serum urea and $\mathrm{Cr}$ (Table $1)$. Same results were reported in prior reports $(29,30)$. It is generally accepted that the toxicity of DIC is strongly associated with oxidative stress leading to lipid peroxidation and injury to the cellular macromolecules $(7,31)$. In groups 3 and 4 DIC-induced deteriorations reduced by silymarin treatment which are in agreement with prior investigations $(32,33)$. On the other hand, this renal protective effect of silymarin may be due to its stabilizing effects on plasma membrane and proteins against reactive oxygen species (ROS).

In our research, the injection of DIC not only led to a remarkable reduction in activities of SOD and CAT but also 



Figure 2. Effects of Silymarin on the renal histopathology of experimental groups. (A) Control group with normal structure; (B) diclofenac-injected rats without treatment show lymphocyte infiltration (the black arrows); (C) diclofenac-injected rats supplemented with silymarin (100 mg/kg bw); (D) diclofenac-injected rats supplemented with silymarin $(200 \mathrm{mg} / \mathrm{kg} \mathrm{bw})$.

caused a notable increase in MDA contents relative to the normal group. This can be due to the formation of surplus free radicals produced by metabolites of DIC that defeat the antioxidant system and result in lipids peroxidation. These results are in line with prior investigations $(22,34)$. The administration of silymarin in third and fourth groups causes a noticeable elevation in activities of SOD and CAT relative to those rats in second group (DIC-only treated group). Silymarin has antioxidant properties and stabilizes the membrane $(27,35)$. The noticeable increase in CAT and SOD activities and decrease in MDA contents of the animals treated with 100 and $200 \mathrm{mg} / \mathrm{kg}$ doses of silymarin (groups 3 and 4) demonstrate the decrease of free radicals. Also, histopathological studies depicted that mononuclear cells infiltration was reduced in treated rats with 100 and $200 \mathrm{mg} / \mathrm{kg}$ doses of silymarin (groups 3 and 4) (Figure 2). Thus, it is indicated that silymarin severely scavenges free radicals and stabilizes renal cell membrane by removing poisonous oxidative species via detoxification system of body, thereby protecting the kidney tissues from injury. Furthermore, in our research treatment with silymarin in groups 2 and 3 caused a remarkable elevation in levels of plasma FRAP (Table 2) that approved antioxidant properties of silymarin and can be considered as a reason for elevation of CAT and SOD and reduction of MDA in silymarin-treated groups.

Vitamin $\mathrm{C}$ is responsible for destroying and scavenging free radicals as a non-enzymatic antioxidant (36). It inhibits the release of free radicals which can prevent primary and secondary oxidation of nucleic acids, proteins and lipids (37). The reduced content of ascorbic acid in DIC treated animals (group 1) may be because of the elevated usage as an antioxidant defense against elevated ROS or reduction of glutathione content, since glutathione is needed for the recycling of vitamin C (38). However, administration of silymarin increased vitamin $\mathrm{C}$ in the treated groups compared with its level in group 2 (administration DIC only) which is in agreement with the findings of previous studies $(22,39,40)$. Thus, the increase of vitamin C can be considered a reason for reducing ROS in silymarin-treated groups and the recuperation of renal damage and morphological changes.

Inflammatory cytokines and chemokines play a main role in nephrotoxicity induced by DIC (41). TNF- $\alpha$ is a cytokine which releases the inflammatory conditions and migration of macrophages. TNF- $\alpha$ leads to oxidative stress which in turn increases the renal cells damage. Previous findings also demonstrated that TNF- $\alpha$ gene expression was elevated in renal damages (22,42-44). In our research, there was a noticeable elevation in both serum level and renal expression of TNF- $\alpha$ in the animals of second group (DIC- only treated group) compared to the normal group (Figure 1). Also histopathological examinations confirmed inflammation in kidney tissues of DIC-treated rats (Figure 2). Nevertheless, oral injection of silymarin at doses of 100 or $200 \mathrm{mg} / \mathrm{kg}$ after treatment with DIC led to a remarkable reduction in the levels of this parameter which is in agreement with histopathological findings in these groups. Thus, the decrease in levels of serum TNF- $\alpha$ and expression of TNF- $\alpha$ gene is an acceptable evidence that confirms the nephroprotective role of silymarin because of its antioxidant properties. Accordingly, because of the growing trend in the use of NSAIDs around the world, we offer that future investigations focusing on the probable roles of silymarin on the injury induced by DIC on other vital organs.

\section{Conclusion}

In conclusion, our research approved the protective role of silymarin against renal damage induced by diclofenac in rats because not only it decreases renal inflammatory cells, lipid peroxidation and TNF- $\alpha$, but also elevates kidney activities of vitamin C, CAT, and SOD.

\section{Acknowledgments}

We would like to express our gratitude to the staff of Clinical Biochemistry Research Center of Shahrekord University of Medical Sciences who helped us.

\section{Authors' contributions}

Designing the study, data analysis and preparation of the manuscript was done by AN and EH. Authors read and approved the final manuscript.

\section{Conflict of interests}

The authors declared no competing interests. 


\section{Ethical considerations}

The study was approved by the Ethical Committee of Shahrekord University of Medical Sciences, Shahrekord, Iran (Ethic number: IR. SKUMS. REC. 94. 146). Ethical issues (including plagiarism, data fabrication, double publication) have been completely observed by the authors.

\section{Funding/Support}

This research was financially supported by Shahrekord University of Medical Sciences, Shahrekord, Iran (grant no. 2640).

\section{References}

1. Hickey E, Raje R, Reid V, Gross S, Ray S. Diclofenac induced in vivo nephrotoxicity may involve oxidative stress-mediated massive genomic DNA fragmentation and apoptotic cell death. Free Radic Biol Med. 2001;31(2):13952. doi: 10.1016/S0891-5849(01)00560-3.

2. Gierse JK, Hauser SD, Creely DP, Koboldt C, Rangwala $\mathrm{SH}$, Isakson PC, et al. Expression and selective inhibition of the constitutive and inducible forms of human cyclooxygenase. Biochem J. 1995;305(2):479-84. doi: 10.1042/ bj3050479.

3. Laneuville O, Breuer DK, Dewitt DL, Hla T, Funk CD, Smith WL. Differential inhibition of human prostaglandin endoperoxide $\mathrm{H}$ synthases-1 and-2 by nonsteroidal anti-inflammatory drugs. J Pharmacol Exp Ther. 1994;271(2):927-34.

4. Blair HA, Plosker GL. Diclofenac sodium injection (Akis ${ }^{\circledR}$, Dicloin ${ }^{\star}$ ): a review of its use in the management of pain. Clin Drug Investig. 2015;35(6):397-404. doi: 10.1007/ s40261-015-0294-6.

5. Hoy SM. Diclofenac sodium bolus injection (Dyloject ${ }^{\mathrm{TM}}$ ): A review in acute pain management. Drugs. 2016;76(12):121320.

6. Hossain MK, Khatun A, Rahman M, Akter MN, Chowdhury SA, Alam SM. Characterization of the effect of drug-drug interaction on protein binding in concurrent administration of sulfamethoxazol and diclofenac sodium using bovine serum albumin. Adv Pharm Bull. 2016;6(4):589.

7. Lonappan L, Brar SK, Das RK, Verma M, Surampalli RY. Diclofenac and its transformation products: environmental occurrence and toxicity-a review. Environ Int. 2016;96:12738. doi: 10.1016/j.envint.2016.09.014.

8. Brogden R, Heel R, Pakes G, Speight TM, Avery G. Diclofenac sodium: a review of its pharmacological properties and therapeutic use in rheumatic diseases and pain of varying origin. Drugs. 1980;20(1):24-48.

9. Wellington K, Jarvis B. Silymarin: a review of its clinical properties in the management of hepatic disorders. BioDrugs. 2001;15(7):465-89. doi: 10.2165/00063030200115070-00005

10. Borsari M, Gabbi C, Ghelfi F, Grandi R, Saladini M, Severi $\mathrm{S}$, et al. Silybin, a new iron-chelating agent. J Inorg Biochem. 2001;85(2-3):123-9.

11. Müzes G, Deák G, Láng I, Nékám K, Niederland V, Fehér J. Effect of silimarin (Legalon) therapy on the antioxidant defense mechanism and lipid peroxidation in alcoholic liver disease (double blind protocol). Orv Hetil. 1990;131(16):863-6.

12. Aydin G, Gökçimen A, Öncü M, Çicek E, Karahan N, Gökalp O. Histopathologic changes in liver and renal tissues induced by different doses of diclofenac sodium in rats. Turk J Vet Anim Sci. 2003;27(5):1131-40. doi: 10.1191/0960327103ht354oa.

13. Giridharan R, Sabina EP. Suppressive effect of Spirulina fusiformis on diclofenac-induced hepato-renal injury and gastrointestinal ulcer in Wistar albino rats: a biochemical and histological approach. Biomed Pharmacother. 2017;88:11-8. doi: 10.1016/j.biopha.2017.01.032.

14. Kropacova K, Misurova E, Hakova H. Protective and therapeutic effect of silymarin on the development of latent liver damage. Radiats Biol Radioecol. 1998;38(3):411-5.

15. Bruschetta G, Impellizzeri D, Siracusa R, Di Paola R, Paterniti I, Prosdocimi M, et al. Effects of palmitoylethanolamide and silymarin combination therapy in an animal model of kidney ischemia and reperfusion. FASEB J. 2015;29(1_ supplement):1026.3.

16. Zaidi F, Nuzhat S, Mahboob T. Prevention of liver cirrhosis by Silymarin. Pak J Pharm Sci. 2017;30(4): 1-6.

17. Heidarian E, Soofiniya Y. Hypolipidemic and hypoglycemic effects of aerial part of Cynara scolymus in streptozotocininduced diabetic rats. J Med Plant Res. 2011;5(13):2717-23.

18. Omaye ST, Turnbull JD, Sauberlich HE. Selected methods for the determination of ascorbic acid in animal cells, tissues, and fluids. Methods in Enzymology: Elsevier; 1979; 62: 3-11.

19. Heidarian E, Saffari J, Jafari-Dehkordi E. Hepatoprotective action of Echinophora platyloba DC leaves against acute toxicity of acetaminophen in rats. J Diet Suppl. 2014;11(1):53-63. doi: 10.3109/19390211.2013.859217.

20. Flohé L, Otting F. Methods in enzymology. Oxygen radicals in biological systems. New York: Academic Press; 1984:93104.

21. Bradford MM. A rapid and sensitive method for the quantitation of microgram quantities of protein utilizing the principle of protein-dye binding. Anal Biochem. 1976;72(1-2):248-54.

22. Nouri A, Heidarian E, Nikoukar M. Effects of $\mathrm{N}$-acetyl cysteine on oxidative stress and TNF- $\alpha$ gene expression in diclofenac-induced hepatotoxicity in rats. Toxicol Mech Methods. 2017;27(8):561-7. doi: 10.1080/15376516.2017.1334732.

23. Bancroft JD, Gamble M. Theory and practice of histological techniques: Elsevier Health Sciences; 2008.

24. Al-Snafi ae. Therapeutic properties of medicinal plants: a review of their detoxification capacity and protective effects (part 1). Asian Journal of Pharmaceutical Science \& Technology. 2015; 5(4): 257-270.

25. Naughton CA. Drug-induced nephrotoxicity. Am Fam Physician. 2008;78(6):743-50.

26. Loguercio C, Festi D. Silybin and the liver: from basic research to clinical practice. World J Gastroenterol. 2011;17(18):1-6.

27. Saller R, Meier R, Brignoli R. The use of silymarin in the treatment of liver diseases. Drugs. 2001;61(14):2035-63.

28. Hellerbrand C, Schattenberg JM, Peterburs P, Lechner A, Brignoli R. The potential of silymarin for the treatment of 
hepatic disorders. Clin Phytosci. 2017;2(1):7.

29. Fattori V, Borghi SM, Guazelli CF, Giroldo AC, Crespigio J, Bussmann AJ, et al. Vinpocetine reduces diclofenac-induced acute kidney injury through inhibition of oxidative stress, apoptosis, cytokine production, and NF- $\mathrm{KB}$ activation in mice. Pharmacol Res. 2017;120:10-22.

30. Borghi SM, Fattori V, Ruiz-Miyazawa KW, Bertozzi MM, Lourenco-Gonzalez Y, Tatakihara RI, et al. Pyrrolidine dithiocarbamate inhibits mouse acute kidney injury induced by diclofenac by targeting oxidative damage, cytokines and NF- $\kappa B$ activity. Life sci. 2018;208:221-31. doi: 10.1016/j.lfs.2018.07.038.

31. Ungprasert P, Cheungpasitporn W, Crowson CS, Matteson EL. Individual non-steroidal anti-inflammatory drugs and risk of acute kidney injury: a systematic review and meta-analysis of observational studies. Eur J Intern Med. 2015;26(4):285-91.

32. Oda SS, El-Ashmawy IM. Protective effect of silymarin on mercury-induced acute nephro-hepatotoxicity in rats. Studies. 2012;35:36. doi: 10.5829/idosi.gv.2012.9.4.6510.

33. Ustyol L, Demirören K, Kandemir I, Erten R, Bulan K, Kaba S, et al. Comparative nephroprotective effects of silymarin, $\mathrm{N}$-acetylcysteine, and thymoquinone against carbon tetrachloride-induced nephrotoxicity in rats. Iran Red Crescent Med J. 2017;19(1).

34. El-Maddawy ZK, El-Ashmawy IM. Hepato-renal and hematological effects of diclofenac sodium in rats. Glob J Pharmacol. 2013;7(2):123-32.

35. Farombi E, Nwaokeafor I. Anti-oxidant mechanisms of kolaviron: studies on serum lipoprotein oxidation, metal chelation and oxidative membrane damage in rats. Clin Exp Pharmacol Physiol. 2005;32(8):667-74. doi: 10.1111/j.03051870.2005.04248.x.

36. Haramaki N, Stewart DB, Aggarwal S, Ikeda H, Reznick AZ, Packer L. Networking antioxidants in the isolated rat heart are selectively depleted by ischemia-reperfusion. Free Radic Biol Med. 1998;25(3):329-39.
37. Nonaka A, Manabe T, Tobe T. Effect of a new synthetic ascorbic acid derivative as a free radical scavenger on the development of acute pancreatitis in mice. Gut. 1991;32(5):528-32.

38. Vennila L, Pugalendi KV. Protective effect of sesamol against myocardial infarction caused by isoproterenol in Wistar rats. Redox Rep. 2010;15(1):36-42.

39. Sharifi-Rigi A, Heidarian E, Amini SA. Protective and anti-inflammatory effects of hydroalcoholic leaf extract of Origanum vulgare on oxidative stress, TNF- $\alpha$ gene expression and liver histological changes in paraquatinduced hepatotoxicity in rats. Arch Physiol Biochem. 2018:1-8. doi: 10.1080/13813455.2018.1437186.

40. Karimi-Khouzani O, Heidarian E, Amini SA. Antiinflammatory and ameliorative effects of gallic acid on fluoxetine-induced oxidative stress and liver damage in rats. Pharmacol Rep. 2017;69(4):830-5. doi: 10.1016/j. pharep.2017.03.011.

41. Kakita H, Aoyama M, Nagaya Y, Asai H, Hussein MH, Suzuki M, et al. Diclofenac enhances proinflammatory cytokine-induced phagocytosis of cultured microglia via nitric oxide production. Toxicol Appl Pharmacol. 2013;268(2):99-105.

42. Krenkel O, Mossanen JC, Tacke F. Immune mechanisms in acetaminophen-induced acute liver failure. Hepatobiliary Surg Nutr. 2014;3(6):331.

43. Fredriksson L, Herpers B, Benedetti G, Matadin Q, Puigvert JC, de Bont $\mathrm{H}$, et al. Diclofenac inhibits tumor necrosis factor- $\alpha$-induced nuclear factor- $\kappa B$ activation causing synergistic hepatocyte apoptosis. Hepatology. 2011;53(6):2027-41.

44. Devrim Dogan M, Ataoglu H, Akarsu ES. Nimesulide and diclofenac inhibit lipopolysaccharide-induced hypothermia and tumour necrosis factor- $\alpha$ elevation in rats. Fundam Clin Pharmacol. 2002;16(4):303-9. doi: 10.1046/j.14728206.2002.00093.x. 